\title{
EDITORIAL Sages of the Profession: Celebration of our Heritage
}

\author{
Gerald T. Powers \\ Virginia Majewski \\ Special Issue Co-Editors
}

The Indiana University School of Social Work recently celebrated its 100-year anniversary as the oldest school of social work continuously affiliated with a university. That seminal occasion served as a compelling reminder of the extraordinary history of our profession and its relentless efforts on behalf of the vulnerable, oppressed and disadvantaged members of society. For more than a decade, the School's journal Advances in Social Work has been devoted to the dissemination of theory and research that supports these efforts of social work educators and practitioners. Thus it seemed only appropriate that we devote a special issue of Advances to a retrospective exploration of some of the critical events in the history of the profession that have contributed to and help shape our present understanding of social work practice and education.

The intent of this special issue is to chronicle the rich heritage of the social work profession and its educational initiatives as seen through the eyes of those who have actually lived and contributed to that heritage. Accordingly, the editorial board felt that the best way to document some of these critical events would be to invite a group of nationally recognized scholars to provide first-person, eyewitness accounts of their observations and direct involvement with the events as they unfolded.

The initial challenge in creating this special issue was to identify a representative group of social work "sages," that is, those individuals with the professional and academic credentials that would qualify them to speak authoritatively about the landmark events and challenges in the history of the profession. The editorial board agreed that the best approach might be to send requests for nominees to all deans and directors of social work programs across the United States and Canada. The request stated, "We are especially interested in capturing the first-hand accounts of our senior colleagues who have either been a part of seminal historical developments within the profession or have been eyewitnesses to those events. The authors will have considerable latitude with respect to the topics they wish to address. Our goal is to provide a forum for the discussion of historical events that have helped shape the culture and direction of the profession and its educational and knowledge-building endeavors."

From an impressive pool of more than 40 highly credentialed nominees, we then contacted a wide range of prospective authors whom we felt would enable us to compile a diverse set of historical documents representative of some of the more significant historical events in the evolution of the profession. The identified prospective authors were then invited to submit manuscripts on topics directly related to their specific areas of expertise.

Gerald T. Powers, Ph.D., is a Professor Emeritus and Virginia Majewski, Ph.D., is a Professor, both in the Indiana University School of Social Work, Indianapolis. 
The response to our invitations was both immediate and enthusiastic. Virtually all of the invited authors indicated a genuine interest in the project. Some indicated that they had to regretfully decline our invitation due to earlier commitments and the tight turnaround time dictated by the publishing deadlines. However, many invited scholars indicated that they were both interested and willing to submit articles. The scholarly products of this initial group of sages appear in the present volume.

Readers may undoubtedly look for sages they know well or for areas of practice and education not covered in this volume. We recognize that our initial group represents a small sample of the many highly distinguished individuals who might submit authoritative documents for such an historical volume. We also recognize that we have not covered all areas of education and practice.

Nonetheless, despite the limitations of our selection process, we have been very encouraged by the enthusiastic response exhibited by our colleagues for an historical initiative designed to capture some of the rich heritage of our profession before it is lost to posterity. Given our success in this limited initiative, and partially because of its limitations, we would like to perpetuate the organizing principle that has informed this volume by creating a more permanent repository for subsequent scholarly manuscripts directly related to the history of social work. By doing so, we hope to provide a forum for authors of the type represented in this special edition to share their unique first-person perspectives on important historical events in the development of the profession. This continuing initiative will be referred to as the Heritage Collection.

As subsequent historical manuscripts that meet the editorial protocol established for both the journal and this present special eyewitness edition are submitted and approved, they will be published in the most current edition of Advances in Social Work and, with the approval of the author, included as part of the compendium of articles comprising the Heritage Collection. Because of the unique enduring nature of these historical documents, it is anticipated that they will provide an invaluable resource for researchers, faculty compiling course syllabi, or anyone interested in the origins and development of the profession. In addition, the Collection will provide a forum for scholars to compare and contrast individual perceptions of the same historical events.

Our editorial decision was to present the seventeen manuscripts in alphabetical order by primary author name. Each scholarly contribution stands alone in the author's or coauthors' presentation and interpretation of salient historical events and her/his/their unique involvement in these events. Nonetheless readers will see some overlap in terms of such topics as the growth of professional education, research infrastructure for social work, evolution of theoretical approaches and frameworks for practice, ethics and philosophy, diversity and oppression, and pioneer efforts in fields of practice such as child welfare and mental health.

Due in part to the direct eyewitness nature of many of the historical accounts, the authors chose to write in the atypical first-person. This more colloquial approach contributed to the kind and level of authenticity that can only be achieved by someone who has "been there and done that." In many instances, the content of the articles provides intriguing insights, not only into the nature of the subject matter under 
consideration, but also into the character of the authors as they struggled to make meaningful changes with respect to the issues with which they grappled.

The editing of this special issue has proven to be a most rewarding and informative learning experience. We have been privileged to be able to communicate and interact with so many noted scholars and pioneers of our profession. We have been struck by the care and sensitivity with which our cohort of authors approached their subject matter. Several indicated that at times, their journey into the past precipitated a sense of nostalgia, and in some instances, painful memories. Nevertheless, a common reaction to having participated in these historical sojourns has been one of satisfaction and fulfillment. In every instance, their manuscripts reveal how passionately the authors feel about the subjects on which they've written and devoted important segments of their lives. We extend sincere thanks and appreciation to all our contributing sages and to those who will consider contributing in the future to the Heritage Collection.

\section{Author note}

Address correspondence to Gerald T. Powers, Ph.D., Professor Emeritus, Indiana University School of Social Work, 902 W. New York St., Indianapolis, IN 46202-5156. E-mail: gpowers@iupui.edu
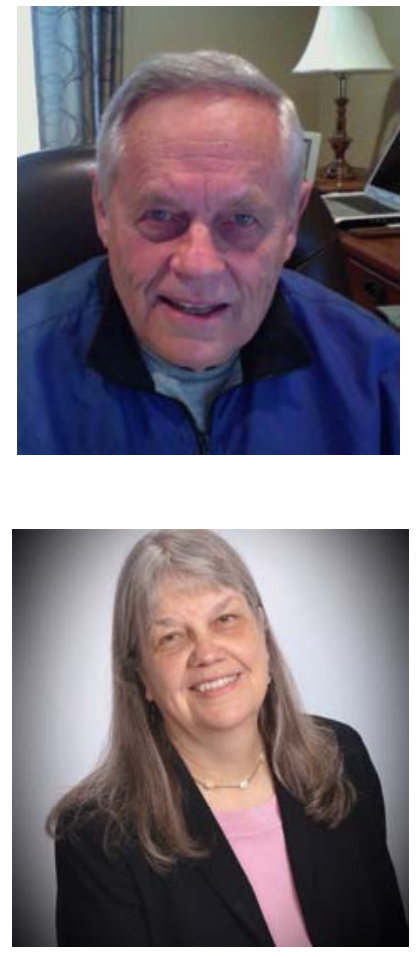

Gerald (Jerry) Powers earned his baccalaureate degree in sociology and philosophy from the University of Scranton, an MSW degree at Fordham University, a PhD at the University of Pittsburgh, and did post graduate work at the University of Chicago. During his 37-year affiliation with the IU School of Social Work, he was instrumental in the development and accreditation of the PhD Program and served as its founding Director during its first nine years. He also served as Acting Dean of the School from 1983 thru 1985. His teaching, research and published scholarship, including a research text entitled Practice-Focused Research, have emphasized practice evaluation research, the scholarship of teaching and learning, strengths-based social work and resilience theory. Jerry has several University Awards, including induction into the Indiana University Faculty Colloquium on Excellence in Teaching (FACET) in 1990 and was recently recognized by that organization with the prestigious Honorary PA Mack Award for Distinguished Service to Teaching. He was a Captain in the US Army having served as an army social work officer at Brooke Army Hospital in San Antonio, TX and the Irwin Army Hospital at Fort Riley, KS.

Virginia (Ginny) Majewski serves as Professor in the Indiana University School of Social Work. She holds a Master of Arts in Hispanic Languages/Latin American Studies, Master of Social Work, and doctorate in Public and International Affairs from the University of Pittsburgh. In 2013, she received the Distinguished Alumni Award from the University of Pittsburgh School of Social Work. She recently served the IU School of Social Work as Associate Dean, and before as Chairperson and MSW Director at West Virginia University, and Chairperson and BSW Director at California University of Pennsylvania. Dr. Majewski's teaching, service, and scholarship revolve around her commitment to service and experiential learning to enhance professional competence. In 2007, she co-edited the book Social Work and Service Learning: Partnerships for Social Justice and has presented extensively in this area in national and international venues. She is also active in the National Rural Social Work Caucus and focuses on food insecurity, indigenous issues, and community organizing. 